\title{
HUBUNGAN POLA MAKAN DAN AKTIVITAS FISIK ANAK DENGAN OBESITAS PADA ANAK USIA SEKOLAH DASAR DI SDN KAUMAN 1 MALANG.
}

\author{
FEBRI ENDRA BUDI SETYAWAN*
}

\begin{abstract}
ABSTRAK
Obesitas pada anak merupakan masalah yang kompleks dimana prevalensi di negara-negara maju maupun berkembang terus mengalami kenaikan. Prevalensi obesitas anak di Indonesia mencapai 12.2\% pada tabun 2002-2005. Masalab obesitas ini dikaitkan dengan perubahan pola makan dan aktivitas fisik. Penelitian ini bertujuan untuk mengetabui bubungan pola makan dan aktivitas fisik anak dengan obesitas pada anak usia sekolah dasar. Metode yang digunakan dalam penelitian ini adalah deskriptif analitik dengan pendekatan cross sectional. Penelitian dilakukan pada 44 anak penderita obesitas. Usia penderita obisitas anak paling dominan adalah usia 8 tabun (28\%) dan jenis kelamin terbanyak adalah perempuan (52\%). Uji korelasi didapatkan (r) pola makan 0.018 dan (r) aktivitas fisik 0.024 terhadap Z-skor BB/TB < sig. korelasi 0.05. Uji regresi linier didapatkan (F) 3.910 dengan sig. $0.028<0.05$. Dapat disimpulk.an bahwa obesitas pada anak usia sekolah dasar lebih banyak dijumpai pada anak usia 8 tabun dan berjenis kelamin perempuan. Faktor pola makan dan aktivitas fisik berbubungan sebagai faktor terjadinya obesitas usia anak sekolab dasar.
\end{abstract}

Kata Kunci: Obesitas Anak, Pola Makan, Aktivitas Fisik.

* Staff Pengajar di Fakultas Kedokteran Universitas Muhammadiyah Malang. 
$48 \quad$ Vol. 8 No. 1 Tahun 2014

\title{
THE RELATIONSHIP BETWEEN FOOD PATTERN AND OBESED CHILDREN'S ACTIVITIES IN SDN KAUMAN 1 MALANG.
}

\begin{abstract}
Children obesity is the complex problem in which the prevalence both in developed and developing countries is increasing. The prevalence obesity in Indonesia reached 12.2\% in the year 2002-2005. This problem is related to the change of food pattern and activities. The Objective to understanding the relationship of food pattern and obesed children's activities. This research is a analytic descriptive with cross sectional method. Results this research included 44 obesity children. The age of children was 8 dominantly (28\%) and the most sex is female (52\%). Correlation test revealed (r) 0.018 of food pattern and $(r) 0.024$ of activities with Z-score WHO < sig. correlation 0.05 . Linier regretion test revealed (F) 3.910 with sig. $0.028<0.05$. The conclusions is obesity in childhood was commonly occured among children aging 8 years and females. Diet rules and activities constituted factors of childhood obesity.
\end{abstract}

Keywords: Childhood Obesity, Food Pattern, Activities 


\section{PENDAHULUAN}

\section{Latar Belakang}

Masalah gizi pada anak di Indonesia akhirakhir ini menunjukkan masalah gizi ganda, dimana saat masih terus berkutat dalam menghadapi gizi kurang, dilain pihak pada golongan masyarakat tertentu mulai menghadapi masalah obesitas karena obesitas pada anak mempunyai konsekuensi medis yang serius terutama untuk masa depan yang bersangkutan maupun terhadap ketersediaan kualitas manusia Indonesia selanjutnya (Subardja, 2004).

Obesitas pada anak merupakan masalah yang sangat kompleks antara lain berkaitan dengan kualitas makanan yang dikonsumsi oleh seseorang, perubahan pola makan menjadi makanan cepat saji yang memiliki kandungan kalori dan lemak yang tinggi, waktu yang dihabiskan untuk makan, waktu pertama kali anak mendapat asupan berupa makanan padat, kurangnya aktivitas fisik, faktor genetik, hormonal dan lingkungan (Suarthana, 2007).

Meskipun tidak mudah mendapatkan data yang akurat mengenai jumlah dan prevalensi kegemukan dan obesitas pada anak di Indonesia, penelitian yang dilakukan oleh Dr. Damayanti bersama koleganya yang tergabung dalam Masyarakat Pediatrik Indonesia di sepuluh kota besar di Indonesia periode 2002-2005, hasilnya prevalensi pada anak-anak usia sekolah dasar secara urut Jakarta ada di posisi pertama dengan 25\%, disusul Semarang 24.3\%, Medan 17.75\%, Denpasar $11.7 \%$, Surabaya $11.4 \%$, Padang $7.1 \%$, Manado $5.3 \%$, Yogyakarta 4\% dan Solo $2.1 \%$ dengan ratarata prevalensi di Indonesia $12.2 \%$. Angka prevalensi obesitas ini hampir sama dengan obesitas anak di Inggris, antara $10 \%$ sampai $17 \%$, dan Amerika, antara 10\% sampai 12\% (Wahyu, 2009).

Sementara itu data dari Dinas Kesehatan Kota Malang tahun 2007 mengatakan bahwa 6\% anak laki-laki dan 5.9\% anak perempuan dari 74.837 anak usia sekolah dasar di Kota Malang menderita obesitas. Nilai ini tidak jauh berbeda dengan prevalensi obesitas anak di kabupaten lain di Jawa Timur dimana rata-rata $11.1 \%$ untuk anak laki-laki dan 6.5\% untuk anak perempuan (Dinkes Kota Malang, 2013).

Obesitas pada anak telah menjadi salah satu masalah kesehatan paling penting di banyak negara. Seiring dengan meningkatnya obesitas, meningkat pula penyakit-penyakit yang terkait dengannya. Obesitas mempunyai dampak terhadap tumbuh kembang anak terutama dalam aspek organik dan psikososial serta akan beresiko tinggi menjadi obesitas pada masa dewasanya (Suarthana $\mathrm{dkk}, 2007)$.

Pola aktivitas yang minim berperan besar dalam peningkatan risiko obesitas pada anak. Obesitas pada anak yang kurang aktivitas fisik disebabkan oleh jumlah kalori yang dibakar lebih sedikit dibandingkan jumlah kalori yang diperoleh dari makanan yang dikonsumsi sehingga berpotensi menimbulkan penimbunan lemak berlebih di dalam tubuh (Wahyu, 2009). Mengingat tingginya prevalensi obesitas pada anak yang dikaitkan dengan perubahan pola makan dan kurangnya aktifitas fisik, maka diperlukan penelitian lebih lanjut guna mengetahui hubungan pola makan dan aktifitas fisik anak dengan obesitas.

SDN Kauman 1 Malang merupakan sekolah dasar yang mempunyai prevalensi obesitas yang cukup tinggi di kota Malang. Dari hasil penelitian pendahuluan didapatkan prevalensi penderita obesitas mencapai $15.7 \%$. Sementara itu tingkat sosial ekonomi wali murid juga terdapat pada golongan menengah keatas. Hal ini diasumsikan bahwa akan terjadi perubahan pola makan dan minimnya aktivitas fisik pada anak.

Berdasarkan data tersebut diatas, maka peneliti ingin mengetahui Hubungan Pola Makan Dan Aktivitas Fisik Anak Dengan Obesitas Pada Usia Anak Sekolah Dasar di SDN Kauman 1 Malang.

Rumusan Masalah

Apakah terdapat hubungan pola makan dan aktivitas fisik anak dengan obesitas pada usia anak sekolah dasar di SDN Kauman 1 Malang?

\section{Tujuan Penelitian}

Tujuan umum

Mengetahui hubungan antara pola makan dan aktifitas fisik pada anak dengan obesitas pada usia anak sekolah dasar di SDN Kauman 1 Malang. Tujuan khusus

1. Mengetahui pola makan anak penderita obesitas pada usia sekolah dasar di SDN Kauman 1 Malang. 
2. Mengetahui katagori aktifitas fisik anak yang menderita obesitas pada usia sekolah dasar di SDN Kauman 1 Malang.

3. Mengetahui prevalensi anak penderita obesitas usia sekolah dasar di SDN Kauman 1 Malang

Manfaat Penelitian

Manfaat klinis

1. Memberikan informasi mengenai obesitas anak serta hubungan pola makan anak dan aktifitas fisik anak penderita obesitas usia sekolah dasar di SDN Kauman 1 Malang

2. Memberikan wacana kepada masyarakat mengenai dampak obesitas pada anak

Manfaat akademis

Dapat digunakan sebagai salah satu dasar penelitian lebih lanjut

\section{METODE PENELITIAN}

Jenis Penelitian

Jenis penelitian ini adalah penelitian observasional analitik dengan rancangan penelitian yang digunakan adalah metode Cross Sectoinal Study untuk mengetahui hubungan pola makan dan aktivitas fisik anak dengan obesitas pada usia anak sekolah dasar di SDN Kauman 1 Malang.

Tempat dan Waktu Penelitian

$$
\begin{aligned}
& \text { Tempat : SDN Kauman } 1 \text { Malang } \\
& \text { Waktu : Oktober s/d Desember }
\end{aligned}
$$

$$
2013
$$

Populasi dan Sampel

Populasi

Populasi dari penelitian ini adalah seluruh siswa dan siswi SDN Kauman 1 Malang

Sampel

Sampel yang digunakan dalam penelitian ini adalah anak penderita obesitas usia sekolah dasar di SDN Kauman 1 Malang.

Besar sampel

Untuk menentukan besar sampel dengan tingkat kepercayaan yang dikehendaki 95\% dan ketepatan absolute yang diinginkan sebesar $10 \%$, maka formula yang digunakan dalam menentukan besar sampel adalah sebagai berikut:

$$
\begin{aligned}
\mathrm{n} & =\frac{\mathrm{zá}^{2} \mathrm{PQ}}{\mathrm{d}^{2}} \\
\mathrm{n} & =(1,645)^{2} \times 0,202 \times 0,798 /(0,10)^{2} \\
\mathrm{n} & =43.6 \text { à } 44
\end{aligned}
$$

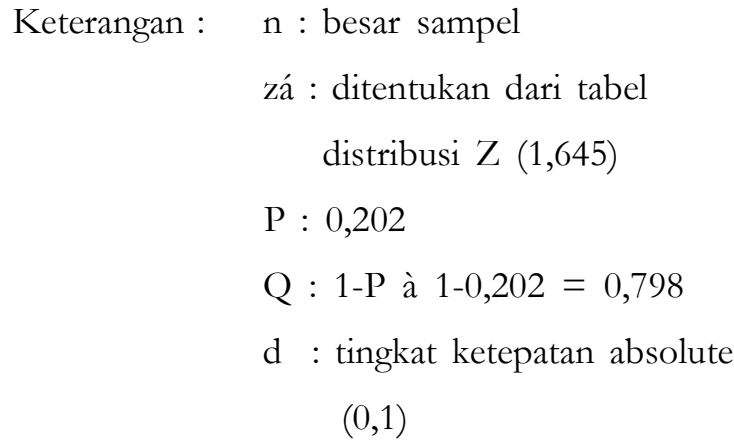

(Sastroasmoro et al,1995)

Tehnik pengambilan sampel

Teknik pengambilan sampel enggunakan metode simple random sampling.

Karakteristik sampel penelitian

A. Kriteria inklusi

a) Anak penderita obesitas

b) Standar Deviasi TB/BB Z-Skor +2 atau lebih

c) Anak usia sekolah dasar dan sedang menuntut ilmu di SDN Kauman 1 Malang

B. Kriteria eklusi

a) Sampel tak masuk sekolah saat penelitian

b) Sedang menjalani program diet khusus

c) Sampel menolak berpartisipasi

$\mathrm{n}=\mathrm{zá}^{2} \mathrm{PQ}$

$d^{2}$

$$
\begin{aligned}
& \mathrm{n}=(1,645)^{2} \times 0,202 \times 0,798 /(0,10)^{2} \\
& \mathrm{n}=43.6 \text { à } 44
\end{aligned}
$$


Keterangan : $\mathrm{n}$ : besar sampel

$$
\begin{aligned}
& \text { zá : ditentukan dari tabel } \\
& \quad \text { distribusi Z (1,645) } \\
& \mathrm{P}: 0,202 \\
& \mathrm{Q} ; \\
& \mathrm{d} \quad \text { 1-P à } 1-0,202=0,798 \\
& \quad \text { tingkat ketepatan absolute }(0,1)
\end{aligned}
$$

Tehnik pengambilan sampel

Teknik pengambilan sampel menggunakan metode simple random sampling. Karakteristik sampel penelitian

A. Kriteria inklusi

a) Anak penderita obesitas

b) Standar Deviasi TB/BB Z-Skor +2 atau lebih

c) Anak usia sekolah dasar dan sedang menuntut ilmu di SDN Kauman 1 Malang

\section{B. Kriteria eklusi}

a) Sampel tak masuk sekolah saat penelitian

b) Sedang menjalani program diet khusus

c) Sampel menolak berpartisipasi

Variabel Penelitian

Variabel bebas

Pola makan (jumlah susu yang diminum, frekuensi makan sehari, frekuensi makanan kudapan serta frekuensi makanan cepat saji) dan aktivitas fisik (durasi/lamanya bermain, jenis permainan, waktu menonton TV, cara pergi ke sekolah) pada anak usia sekolah dasar di SDN Kauman 1 Malang. Variabel tergantung

Obesitas pada anak usia sekolah dasar di SDN Kauman 1 Malang

\section{Definisi Operasional}

1. Obesitas pada anak adalah kondisi dimana standart deviasi Z-Skor TB/BB e" +2 SD

2. Pola makan adalah kuantitas dan kualitas makan yang dikonsumsi meliputi:

a) Jumlah susu yang diminum adalah penggambaran jumlah konsumsi lemak b) Frekuensi makan sehari adalah penggambaran kengkonsumsi karbohidrat setiap harinya

c) Frekuensi makan kudapan adalah pola makan tambahan di luar makan normal

d) Frekuensi makan makanan cepat saji adalah konsumsi makanan dengan kadar kalori yang sangat tinggi, rendah serat dan gizi lainnya.

Dari berbagai determinan diatas akan digambarkan kedalam kategori pola makan baik, cukup baik dan kurang baik berdasarkan pada kuesioner.

3. Aktivitas fisik adalah durasi dan jenis aktivitas yang mengeluarkan energi yang dilakukan anak setiap harinya meliputi:

a) Durasi atau lamanya bermain adalah lama aktivitas anak yang mengeluarkan energi

b) Jenis permainan adalah jenis aktivitas anak yang mengeluarkan dimana usia anak banyak dilakukan aktivitas bermain

c) Waktu menonton TV adalah jenis aktivitas anak yang tidak banyak mengeluarkan energi

d) Cara pergi ke sekolah adalah jenis aktivitas anak yang mengeluarkan energi diluar bermain.

Dari berbagai determinan diatas akan digambarkan kedalam kategori aktivitas fisik baik, cukup baik dan kurang baik berdasarkan pada kuesioner.

Alat Penelitian

a) Timbangan BB

b) Pita meteran dan segitiga siku-siku

c) Tabel TB/BB Z-Skor

d) Kuesioner

Prosedur Penelitian

Data penelitian yang dikumpulkan meliputi data hasil pengukuran tinggi badan (TB) dan berat badan (BB) serta pengisian kuesioner yang telah 
diuji coba. Kuesioner meliputi data informasi deskriptif tentang pola makan sehari-hari meliputi jumlah susu yang diminum, frekuensi makan sehari, frekuensi makanan kudapan serta frekuensi makan makanan cepat saji serta informasi deskriptif tentang aktivitas fisik meliputi waktu/lamanya bermain, jenis permainan, waktu menonton TV dan cara pergi ke sekolah.

Pengukuran berat badan dilakukan dengan menggunakan timbangan yang telah distandarisasi dengan ketelitian $0,1 \mathrm{Kg}$, sedang pengukuran tingi badan dilakukan dengan menggunakan pita meteran dan segitiga siku-siku. Dari pengukuran tersebut kemudian dikembangkan antropometri turunan yaitu status gizi berdasarkan TB/BB, selanjutnya data antropometri turunan tersebut diklasifikasikan dalam status gizi yaitu diklasifikasikan berdasar SD Z-Skor.

Penilaian pola makan serta aktifitas fisik dilakukan dengan menggunakan tabel kuesioner. Uji validitas kuesioner menggunakan teknik korelasi product moment, sedang uji reabilitas menggunakan rumus Alpha.

a. Prosedur pengukuran tinggi badan:

1. Pilih lantai yang rata dan dinding memenuhi syarat:

2. Dinding harus tegak lurus dengan lantai

3. Bagian dinding yang rata tidak kurang lebar dari bahu anak

4. Jangan pilih dinding yang bagian bawahnya menonjol

5. Pasang pita meteran tegak lurus dengan lantai dengan angka 0 tepat dilantai

6. Posisikan anak secara benar dengan posisi anak membelakangi pita, tidak boleh pakai sepatu, tumit rapat dan kepala menempel ke dinding, pandangan lurus

7. Baca hasil

b. Prosedur pengukuran berat badan

1. Periksa alat timbang

2. Proses penimbangan anak tak memakai sepatu atau membawa barang

3. Pembacaan dan pencatatan hasil

(Fajar,dkk.2002)

Uji Validitas Dan Reliabilitas

Dalam penelitian ini data diperoleh dari data primer dengan menggunakan kuesioner tertutup yang langsung diberikan kepada responden. Sebelum kuesioner ini digunakan, harus diuji terlebih dahulu dengan menggunakan uji validitas dan reliabilitas. Pada suatu tes, validitas dan reliabilitas merupakan syarat yang harus dipenuhi untuk bisa dikatakan sebagai alat yang baik (Notoadmodjo, 2005).

Uji validitas

Uji validitas yang dipakai adalah teknik korelasi product moment 
4.9 Kerangka Operasional

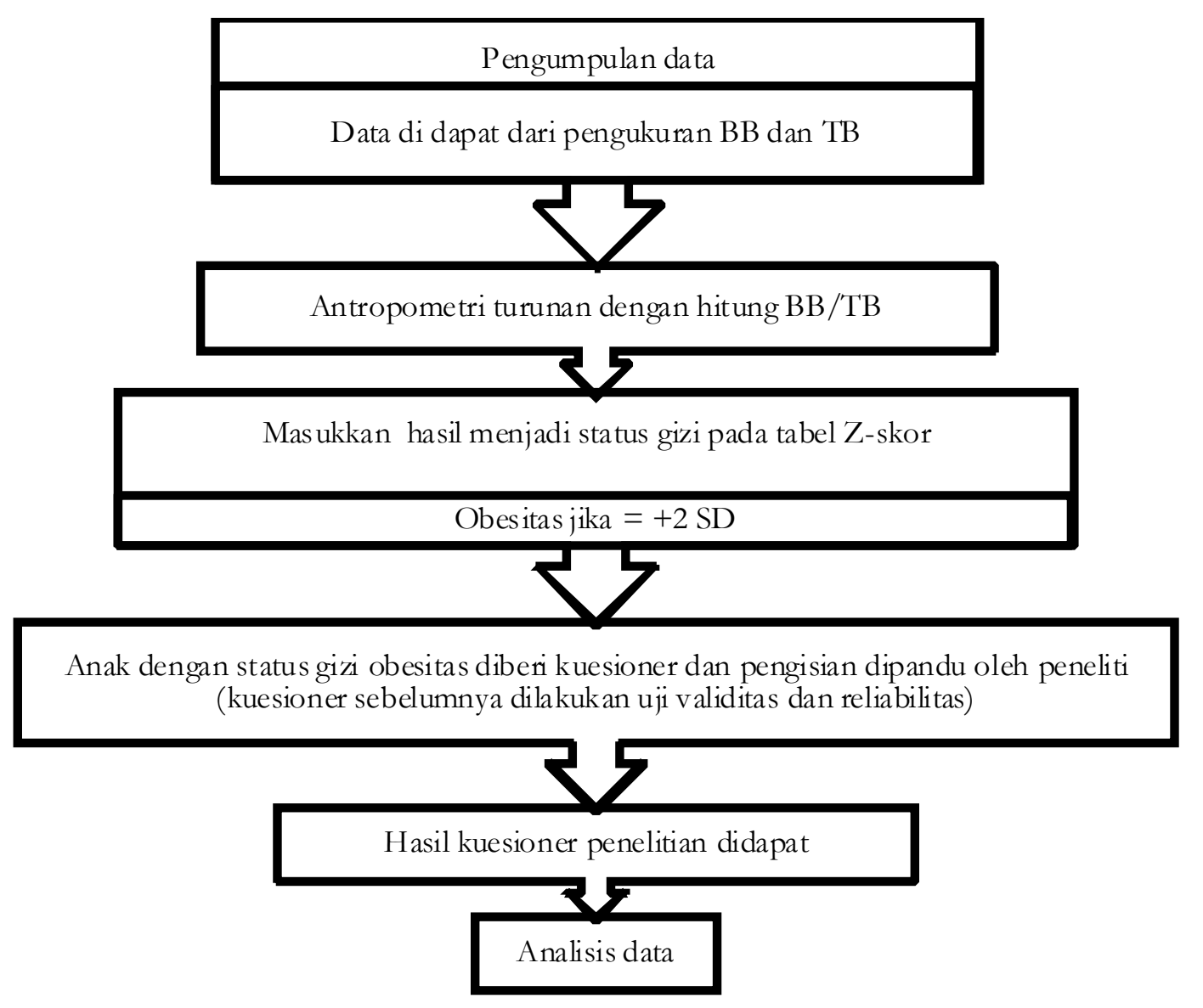

Gambar 4.1

Alur penelitian

Uji reliabilitas

Uji reabilitas pada kuesioner ini dilakukan dengan rumus Alpha.

Analisis Data

Hasil jawaban dari pengisian kuesioner diolah terlebih dahulu melalui kriteria definisi operasional yang telah ditetapkan. Data akan diolah dalam bentuk tabel dan diagram, kemudian untuk mendapatkan data analitik dilakukan uji korelasi product moment, uji regresi multipel dengan menggunakan program SPSS for windows.

\section{HASIL PENELITIAN}

Uji Instrumen Penelitian

Instrumen penelitian yang digunakan pada penelitian ini adalah kuesioner tertutup. Kuesioner yang baik sebelum digunakan untuk penelitian harus dilakukan uji validitas dan reliabilitas, maka dari itu dilakukan uji validitas dan reliabilitas kuesioner kepada 20 responden yang mempunyai sifat dan karakter yang sama dengan sampel.

Uii validitas

Rumus up validitas :

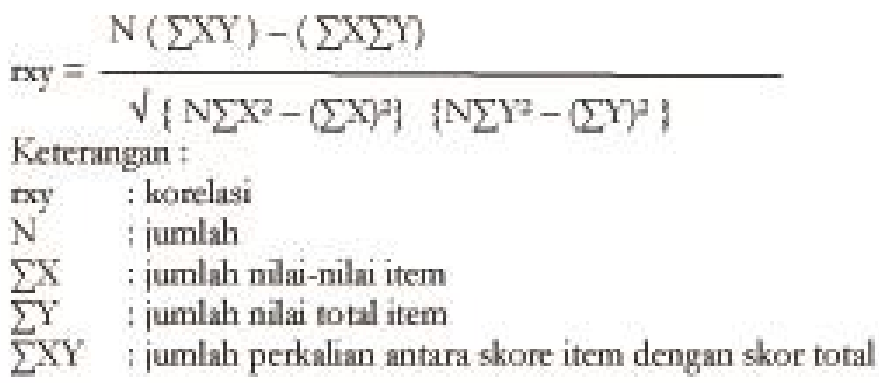


Tabel 5.1 Hasil uji validitas kuesioner pola makan

\begin{tabular}{c|c|c|c}
\hline Item pertanyaan & Rxy & Tabel & Keterangan \\
\hline 1 & 0.697 & 0.444 & valid \\
\hline 2 & 0.848 & 0.444 & valid \\
\hline 3 & 0.764 & 0.444 & valid \\
\hline 4 & 0.611 & 0.444 & valid \\
\hline 5 & 0.742 & 0.444 & valid \\
\hline
\end{tabular}

Sumber : Data primer yang diolah (2013)

Dari hasil perhitungan uji validitas kuesioner tentang variabel pola makan yaitu dengan membandingkan nilai hitung (rxy) dengan nilai tabel, dan didapatkan semua soal uji coba dinyatakan valid karena mempunya nilai (rxy) diatas nilai tabel yaitu 0.444 .

Tabel 5.2 Uji validitas kuesioner aktivitas fisik Item pertanyaan $\mathbf{R x y}$

\begin{tabular}{c|c|c|c}
\hline Item pertanyaan & Rxy & Tabel & Keterangan \\
\hline 1 & 0.888 & 0.444 & valid \\
\hline 2 & 0.878 & 0.444 & valid \\
\hline 3 & 0.813 & 0.444 & valid \\
\hline 4 & 0.628 & 0.444 & valid \\
\hline
\end{tabular}

Sumber : Data primer yang diolah (2013)

Seperti hasil perhitungan uji validitas kuesioner tentang variabel pola makan, semua soal uji coba tentang variabel aktivitas fisik juga dinyatakan valid yaitu nilai hitung (rxy) diatas nilai tabel yaitu 0.444 .

Uji reliabilitas

Rumus Alpha :

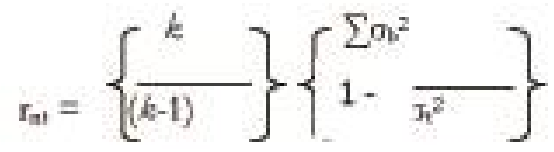

Keterangan :

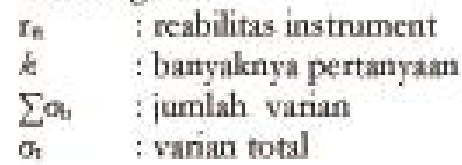

Tabel 5.3 Uji reliabilitas kuesioner

\begin{tabular}{c|c|c|c}
\hline Var. & Cronbach's Alpha & Norma score & Ke simpulan \\
\hline Pola makan & 0.788 & 0.6 & Reliabel \\
\hline Aktivitas fisik & 0.817 & 0.6 & Reliabel \\
\hline
\end{tabular}

Sumber : Data primer yang diolah (2013)

Dari perhitungan uji reliabilitas pada dua variabel diatas didapat nilai alpha diatas norma score, hal ini berarti semua soal uji coba pada kuesioner tersebut telah memenuhi syarat reliabilitas suatu kuesioner dan akhirnya kuesioner dapat digunakan sebagai instrument penelitian.

Gambaran Karakteristik Responden

Dari penelitian yang telah dilakukan, maka didapatkan suatu gambaran karakteristik usia 
responden, jenis kelamin responden, jenjang kelas responden yang disajikan dalam bentuk tabel dan gambar.

Usia responden

Tabel 5.4 Distribusi karakteristik usia responden

\begin{tabular}{c|c|c}
\hline Usia & Frekuensi & $\%$ \\
\hline 6 & 1 & 2 \\
7 & 8 & 18 \\
8 & 12 & 28 \\
9 & 7 & 16 \\
10 & 5 & 12 \\
11 & 5 & 12 \\
12 & 6 & 14 \\
\hline Total & 44 & 100 \\
\hline
\end{tabular}

Sumber : Data primer yang diolah (2013)

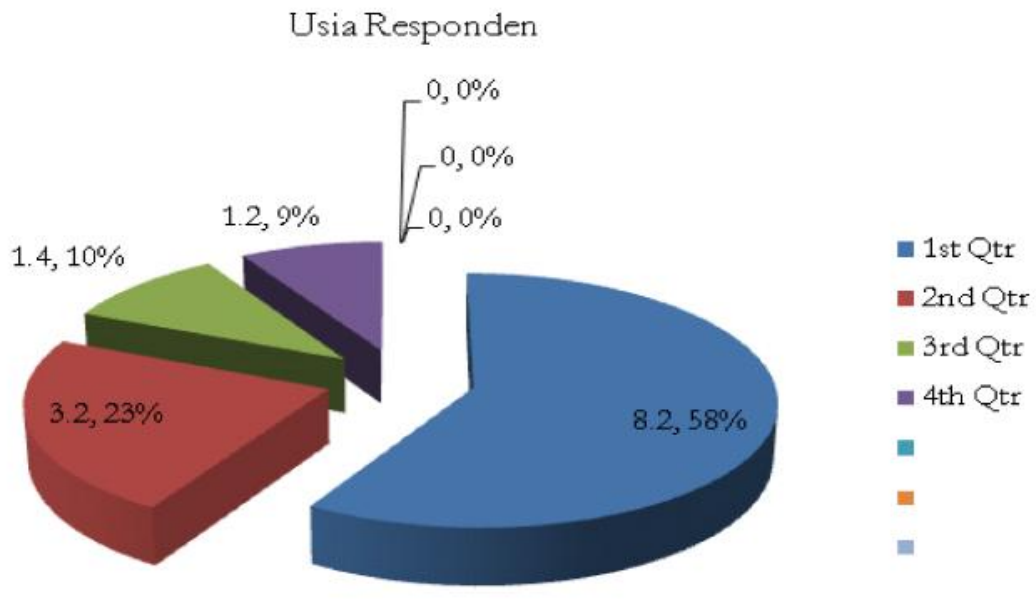

Gambar 5.1

Distribusi usia responden

Dari tabel 5.4 dan gambar 5.1 menunjukkan bahwa sebaran usia responden terbanyak adalah usia 8 tahun dengan persentase $12,27 \%$ responden dan terendah adalah usia 6 tahun terdapat $2 \%$ responden. Jenis kelamin responden

Tabel 5.5 Distribusi karakteristik usia responden

\begin{tabular}{c|c|c}
\hline Jenis Kelamin & Frekuensi & $\mathbf{\%}$ \\
\hline Laki- laki & 21 & 48 \\
Perempuan & 23 & 52 \\
\hline Total & 44 & 100 \\
\hline
\end{tabular}

Sumber : Data primer yang diolah (2013) 
Jenis Kelamin
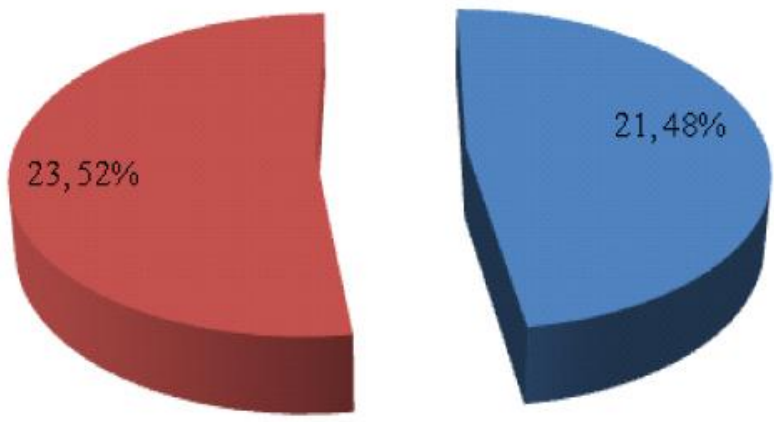

- Laki Laki

Perempuan

Gambar 5.2

Distribusi jenis kelamin responden

Dari tabel 5.5 dan gambar 5.2 menunjukkan bahwa jenis kelamin responden laki-laki terdapat 21 responden (48\%), responden perempuan terdapat 23 responden $(52 \%)$. Dengan demikian responden terbanyak pada penelitian ini adalah berjenis kelamin perempuan.

Jenjang kelas responden

Tabel 5.6 Distribusi karakteristik kelas responden

\begin{tabular}{c|c|c}
\hline Kelas & Frekuensi & \% \\
\hline 1 & 8 & 18 \\
2 & 8 & 18 \\
3 & 11 & 25 \\
4 & 4 & 9 \\
5 & 7 & 16 \\
6 & 6 & 14 \\
\hline Total & 44 & 100 \\
\hline
\end{tabular}

Sumber : Data primer yang diolah (2013)

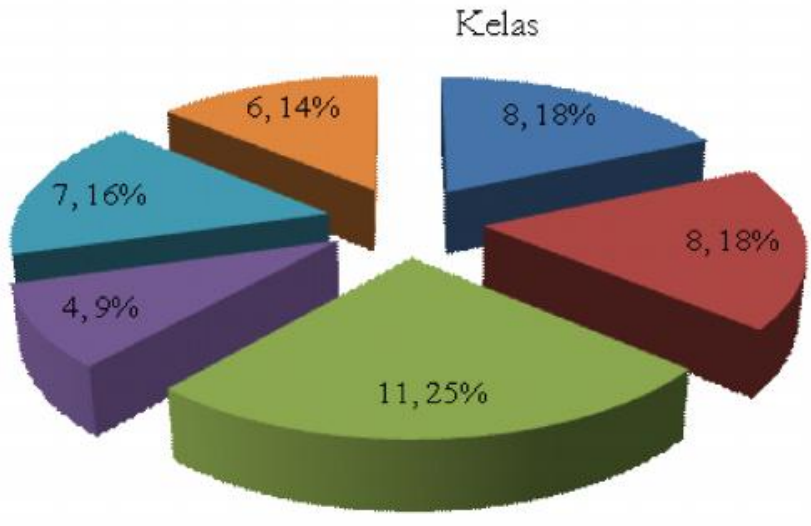

Kelas 1

- Kelas 2

- Kelas 3

- Kelas 4

- Kelas 5

- Kelas 6

Gambar 5.3

Distribusi jenjang kelas responden

Dari tabel 5.6 dan gambar 5.3 menunjukkan bahwa sebaran jenjang kelas responden terbanyak adalah kelas 3 sejumlah 11 responden $(25 \%)$ dan terendah adalah jenjang kelas 4 sejumlah 4 responden $(9 \%)$. 
Distribusi Pola Makan Dan Aktivitas Fisik

\begin{tabular}{|c|c|c|c|c|c|c|}
\hline \multirow[t]{2}{*}{$\begin{array}{c}\text { Pertanyaan } \\
\text { (1) }\end{array}$} & \multicolumn{2}{|c|}{$\begin{array}{c}\text { Jawaban A } \\
>3 \text { gelas }\end{array}$} & \multicolumn{2}{|c|}{$\begin{array}{l}\text { Jawaban } B \\
2-3 \text { gelas }\end{array}$} & \multicolumn{2}{|c|}{$\begin{array}{c}\text { Jawaban C } \\
1 \text { gelas }\end{array}$} \\
\hline & ? & $\%$ & $?$ & $\%$ & $?$ & $\%$ \\
\hline $\begin{array}{l}\text { Berapa gelas dalam sehari anda } \\
\text { minum susu? }\end{array}$ & 7 & 16 & 13 & 30 & 24 & 55 \\
\hline
\end{tabular}

Sumber : Data primer yang diolah (2013)

Dari hasil jawaban kuesioner mengenai jumlah susu yang diminum tiap hari didapat responden terbanyak memilih 1 gelas minum susu perhari sejumlah 55\% responden dan terendah memilih lebih dari 3 gelas minum susu perhari sejumlah 16\% responden dimana 1 gelas susu ukuran rumah tangga sama dengan 110 kalori.

Tabel 5.8 Distribusi frekuensi makan tiap hari

\begin{tabular}{c|c|c|c|c|c|c}
\hline \multirow{2}{*}{$\begin{array}{c}\text { Pertanyaan } \\
(2)\end{array}$} & \multicolumn{2}{c|}{$\begin{array}{c}\text { Jawaban A } \\
5 \mathrm{kali} / \text { lebih }\end{array}$} & \multicolumn{2}{c|}{$\begin{array}{c}\text { Jawaban B } \\
4 \mathrm{kali}\end{array}$} & \multicolumn{2}{c}{$\begin{array}{c}\text { Jawaban C } \\
1-3 \mathrm{Kali}\end{array}$} \\
\cline { 2 - 7 } & $?$ & $\%$ & $?$ & $\%$ & $?$ & $\%$ \\
\hline $\begin{array}{l}\text { Berapa kali dalam sehari anda makan } \\
?\end{array}$ & 1 & 2 & 4 & 9 & 39 & 89 \\
\hline
\end{tabular}

Sumber : Data primer yang diolah (2013)

Dari hasil jawaban kuesioner mengenai frekuensi makan tiap hari didapat dominan responden memilih 1-3 kali perhari hari makan sejumlah $89 \%$ responden dan terendah memilih 5 kali atau lebih yaitu $2 \%$ responden.

Tabel 5.9 Distribusi frekwensi tambah nasi tiap makan

\begin{tabular}{c|c|c|c|c|c|c}
\hline $\begin{array}{c}\text { Pertanyaan } \\
(3)\end{array}$ & \multicolumn{2}{c|}{$\begin{array}{c}\text { Jawaban A } \\
\text { Tidak pernah }\end{array}$} & \multicolumn{2}{c|}{$\begin{array}{c}\text { Jawaban B } \\
\text { kali }\end{array}$} & \multicolumn{2}{c}{$\begin{array}{c}\text { Jawaban C } \\
>1 \text { kali }\end{array}$} \\
\cline { 2 - 7 } & $?$ & $\%$ & $?$ & $\%$ & $?$ & $\%$ \\
\hline $\begin{array}{l}\text { Seberapa sering anda nambah nasi } \\
\text { setiap anda makan? }\end{array}$ & 25 & 57 & 16 & 36 & 3 & 7 \\
\hline
\end{tabular}

Sumber : Data primer yang diolah (2013)

Dari hasil jawaban kuesioner mengenai frekuensi tambah nasi tiap makan didapat responden terbanyak memilih jawaban tidak pernah sebanyak 57\% responden dan terendah memilih nambah nasi lebih dari satu kali tiap makan yaitu $7 \%$ responden.

Dari pertanyaan 2 dan 3 dari determinan pola makan menggambarkan ada 2\% responden yang makan lebih dari 5 kali perhari dan juga terdapat 7\% responden yang nambah nasi lebih dari sekali tiap harinya. Untuk ukuran rumah tangga dalam satu porsi piring nasi menggandung 175 kalori.

Tabel 5.10 Distribusi frekwensi makan makan kudapan

\begin{tabular}{c|c|c|c|c|c|c}
\hline \multirow{2}{*}{$\begin{array}{c}\text { Pertanyaan } \\
\text { (4) }\end{array}$} & \multicolumn{2}{c|}{$\begin{array}{c}\text { Jawaban A } \\
\text { Ya }\end{array}$} & \multicolumn{2}{c|}{$\begin{array}{c}\text { Jawaban B } \\
\text { Jarang }\end{array}$} & \multicolumn{2}{c}{$\begin{array}{c}\text { Jawaban C } \\
\text { Tidak pernah }\end{array}$} \\
\cline { 2 - 7 } & $?$ & $\%$ & $?$ & $\%$ & $?$ & $\%$ \\
\hline $\begin{array}{c}\text { Tiap anda nonton TV, belajar atau } \\
\text { bermain apakah anda sering ngemil ? }\end{array}$ & 15 & 34 & 17 & 39 & 12 & 27 \\
\hline
\end{tabular}

Sumber : Data primer yang diolah (2013)

Dari hasil jawaban kuesioner mengenai frekuensi/keseringan makan makanan kudapan responden terbanyak memilih jawaban jarang 39\% dan terendah memilih jawaban tidak pernah sejumlah $27 \%$ responden. 
Tabel 5.11 Distribusi frekwensi makan makanan cepat saji

\begin{tabular}{l|c|c|c|c|c|c}
\hline $\begin{array}{c}\text { Pertanyaan } \\
(5)\end{array}$ & \multicolumn{2}{c|}{$\begin{array}{c}\text { Jawaban A } \\
1 \text { kali }\end{array}$} & \multicolumn{2}{c|}{$\begin{array}{c}\text { Jawaban B } \\
2-4 \text { kali }\end{array}$} & \multicolumn{2}{c}{$\begin{array}{c}\text { Jawaban C } \\
>4 \text { kali }\end{array}$} \\
\cline { 2 - 7 } & $?$ & $\%$ & $?$ & $\%$ & $?$ & $\%$ \\
\hline $\begin{array}{l}\text { Berapa kali dalam sebulan anda } \\
\text { makan makanan cepat saji ? }\end{array}$ & 19 & 43 & 22 & 50 & 3 & 7 \\
\hline
\end{tabular}

Sumber : Data primer yang diolah (2013)

Dari hasil jawaban kuesioner mengenai frekwensi makan makanan cepat saji dalam sebulan responden dominan memilih 2- 4 kali perbulan yaitu sejumlah 50\% responden dan terendah menjawab lebih dari 4 kali perbulan mengkonsumsi makanan cepat saji sejumlah 7\% responden. Menurut pustaka, makanan cepat saji menggandung tinggi kalori dan rendah nilai gizi dan hampir semua responden dalam sebulannya selalu mengkonsumsi makanan cepat saji tersebut.

Distribusi aktivitas fisik

Dari kuesioner yang dijawab oleh responden mengenai aktivitas fisik telah didapatkan jawaban yang hasilnya dapat didistribusikan sebagai berikut:

Tabel 5.12 Distribusi waktu yang anda gunakan untuk bermain dalam sehari

\begin{tabular}{c|c|c|c|c|c|c}
\hline $\begin{array}{c}\text { Pertanyaan } \\
(1)\end{array}$ & \multicolumn{2}{|c|}{$\begin{array}{c}\text { Jawaban A } \\
1 \text { jam }\end{array}$} & \multicolumn{2}{c|}{$\begin{array}{c}\text { Jawaban B } \\
2-3 \text { jam }\end{array}$} & \multicolumn{2}{c}{$\begin{array}{c}\text { Jawaban C } \\
>3 \text { jam }\end{array}$} \\
\cline { 2 - 7 } & $?$ & $\%$ & $?$ & $\%$ & $?$ & $\%$ \\
\hline $\begin{array}{l}\text { Berapa waktu yang anda gunakan } \\
\text { untuk bermain dalam sehari? }\end{array}$ & 12 & 27 & 19 & 43 & 13 & 30 \\
\hline
\end{tabular}

Sumber : Data primer yang diolah (2013)

Dari hasil jawaban kuesioner mengenai waktu yang digunakan untuk bermain dalam sehari didapat responden terbanyak memilih 2-3 jam waktunya untuk bermain sejumlah 43\% responden dan terendah sejumlah $27 \%$ responden memilih menggunakan watunya satu jam untuk bermain.

Tabel 5.13 Distribusi jenis permainan yang biasa dilakukan

\begin{tabular}{c|c|c|c|c|c|c}
\hline $\begin{array}{c}\text { Pertanyaan } \\
(2)\end{array}$ & \multicolumn{2}{|c|}{$\begin{array}{c}\text { Jawaban A } \\
\text { Play Station / } \\
\text { komputer }\end{array}$} & \multicolumn{2}{|c|}{$\begin{array}{c}\text { Jawaban B } \\
\text { Berkebun, } \\
\text { pelihara } \\
\text { binatang }\end{array}$} & \multicolumn{2}{|c}{$\begin{array}{c}\text { Jawaban C } \\
\text { Bersepeda } \\
\text { lari / s epak } \\
\text { bola }\end{array}$} \\
\cline { 2 - 7 } & $?$ & $\%$ & $?$ & $\%$ & $?$ & $\%$ \\
\hline $\begin{array}{l}\text { Apakah jenis permainan yang biasa } \\
\text { anda lakukan? }\end{array}$ & 24 & 55 & 4 & 9 & 16 & 36 \\
\hline
\end{tabular}

Sumber : Data primer yang diolah (2013)

Dari hasil jawaban kuesioner mengenai jenis permainan yang biasa dilakukan didapat responden terbanyak memilih jenis permainan yang kurang baik (play station, komputer, dll) sebanyak 55\% responden dan pilihan terendah pada jawaban jenis permainan cukup baik (berkebun, memlihara binatang, dll) sebanyak $9 \%$ responden.

Dari pertanyaan durasi bermain dan jenis permainan didapat 30\% responden mengeluarkan waktu bermainnya lebih dari 3 jam dan jenis permainan terdapat 55\% responden memilih bermain play station, komputer dan permainan sejenisnya yang tidak mengeluarkan banyak energi.

Tabel 5.14 Distribusi durasi menonton TV

\begin{tabular}{c|c|c|c|c|c|c}
\hline \multirow{2}{*}{$\begin{array}{c}\text { Pertanyaan } \\
(3)\end{array}$} & \multicolumn{2}{|c|}{$\begin{array}{c}\text { Jawaban A } \\
5 \text { Jam / lebih }\end{array}$} & \multicolumn{2}{c|}{$\begin{array}{c}\text { Jawaban B } \\
3-4 \text { jam }\end{array}$} & \multicolumn{2}{c}{$\begin{array}{c}\text { Jawaban C } 1 \\
-2 \text { jam }\end{array}$} \\
\cline { 2 - 7 } & $?$ & $\%$ & $?$ & $\%$ & $?$ & $\%$ \\
\hline $\begin{array}{c}\text { Berapa lama anda meluangkan waktu } \\
\text { untuk menonton TV dalam sehari? }\end{array}$ & 10 & 23 & 11 & 25 & 23 & 52 \\
\hline
\end{tabular}


Sumber : Data primer yang diolah (2013)

Dari hasil jawaban kuesioner mengenai durasi menonton TV tiap hari responden terbanyak memilih jawaban 1-2 jam untuk menonton TV yaitu 52\% responden dan terendah $23 \%$ responden memilih 5 jam atau lebih menggunakan waktunya untuk menonton TV.

Tabel 5.15 Distribusi cara pergi ke sekolah

\begin{tabular}{c|c|c|c|c|c|c}
\hline \multirow{2}{*}{$\begin{array}{c}\text { Pertanyaan } \\
\text { (4) }\end{array}$} & \multicolumn{2}{c|}{$\begin{array}{c}\text { Jawaban A } \\
\text { Antar jemput }\end{array}$} & \multicolumn{2}{c|}{$\begin{array}{c}\text { Jawaban B } \\
\text { Bersepeda }\end{array}$} & \multicolumn{2}{c}{$\begin{array}{c}\text { Jawaban C } \\
\text { Jalan kaki }\end{array}$} \\
\cline { 3 - 8 } & $?$ & $\%$ & $?$ & $\%$ & $?$ & $\%$ \\
\hline $\begin{array}{c}\text { Dalam pergi ke sekolah, anda } \\
\text { mengendarai apa? }\end{array}$ & 41 & 93 & 3 & 7 & 0 & 0 \\
\hline
\end{tabular}

Sumber : Data primer yang diolah (2013)

Dari hasil jawaban kuesioner mengenai cara pergi ke sekolah tiap hari responden terbanyak menggunakan fasilitas antar jemput untuk pergi ke sekolah sejumlah 93\% responden dan tidak ada responden yang memilih jawaban jalan kaki dalam cara pergi kesekolah.

Analisis data

Dari penelitian pada 44 anak penderita obesitas di SDN Kauman 1 Malang, maka dilakukan uji korelasi dan uji regresi linier untuk menjawab hipotesa penelitian.

\begin{tabular}{c|c|c|c|c}
\hline Variabel & r & Sig. & Keterangan & Ke simpulan \\
\hline Pola makan - obesitas & 0.356 & 0.018 & Sig. $<0.05$ & Signifikan \\
\hline Aktivitas fisik - obesitas & 0.340 & 0.024 & Sig. $<0.05$ & Signifikan \\
\hline
\end{tabular}

Dari tabel rangkuman uji korelasi diatas didapat korelasi yang bermakna antara pola makan dan aktivitas fisik dengan terjadinya obesitas dimana nilai korelasi (r) pola makan terhadap obesitas 0.356 dengan signifikasi 0.018 lebih kecil dari signifikan korelasinya yaitu 0.05 dan nilai korelasi (r) aktifitas fisik 0.340 terhadap obesitas dengan signifikasi 0.024 lebih kecil dari signifikan korelasinya yaitu 0.05 .

Uji regresi multipel

Untuk menjawab hipotesis mengenai hubungan pola makan dan aktivitas fisik anak dengan obesitas pada anak usia sekolah dasar di SDN Kauman 1 Malang maka dilakukan uji regresi linier dan data yang didapat sebagai berikut.

Tabel 5.17 Tabel rangkuman uji regresi multipel

\begin{tabular}{c|c|c|c}
\hline F & Sig. & Keterangan & Kesimpulan \\
\hline 3.910 & 0.028 & Sig $<0.05$ & Signifikan \\
\hline
\end{tabular}

Dari tabel diatas didapat nilai regresi (F) 3.910 dan dengan nilai sig. $0.028<0.05$. Hal ini dapat diartikan bahwa terdapat pengaruh yang signifikan antara pola makan dan aktivitas fisik anak terhadap terjadinya obesitas pada anak usia sekolah dasar di SDN Kauman 1 Malang.

Sementara itu untuk mengetahui faktor risiko mana yang lebih berpengaruh dalam insiden obesitas anak pada usia anak sekolah dasar di SDN KAUMAN 1 Malang maka dilakukan uji signifikansi t, yaitu perkalian nilai korelasi tiap faktor risiko dengan nilai $\beta$ dari tabel koefisien (dilampiran) di kali 100 dan adapun hasilnya sebagai berikut.

Tabel 5.18 Rangkuman uji signifikansi " $\mathrm{t}$ "

\begin{tabular}{l|l|l|l}
\hline Faktor risiko & r & B & $\%$ \\
\hline Pola makan & 0.356 & 0.246 & 8.7576 \\
\hline Aktivitas fisik & 0.340 & 0.214 & 7.2760 \\
\hline
\end{tabular}

Dari hasil perhitungan pada tabel 5.18 diatas didapat bahwa pola makan $(8.7576 \%)$ lebih berpengaruh dari pada korelasi aktivitas fisik $(7.2760 \%)$ dalam kejadian obesitas pada anak usia sekolah dasar di SDN Kauman 1 Malang. 
60 Vol. 8 No. 1 Tahun 2014

Untuk mengetahui gambaran pola makan dan aktivitas fisik anak pada penderita obesitas di SDN Kauman 1 Malang maka dibentuk tabel cross tab/tabulasi silang yang hasilnya disajikan sebagai berikut.

Tabel 5.19 Tabel tabulasi silang pola makan dan aktivitas fisik

\begin{tabular}{|c|c|c|c|c|c|c|}
\hline & \multicolumn{3}{|c|}{ Aktivitas Fisik } & \multirow[t]{2}{*}{ Total } \\
\hline & & & Baik & Cukup Baik & Kurang Baik & \\
\hline \multirow{6}{*}{$\begin{array}{l}\text { Pola } \\
\text { Makan }\end{array}$} & Baik & Jumlah & 9 & 8 & 3 & 20 \\
\hline & & $\%$ total & $20.5 \%$ & $18.2 \%$ & $6.8 \%$ & $45.5 \%$ \\
\hline & Cukup & Jumlah & 5 & 11 & 5 & 21 \\
\hline & Baik & $\%$ total & $11.3 \%$ & $25.0 \%$ & $11.4 \%$ & $47.7 \%$ \\
\hline & Kurang & Jumlah & 0 & 0 & 3 & 3 \\
\hline & Baik & $\%$ total & $0 \%$ & $0 \%$ & $6.8 \%$ & $6.8 \%$ \\
\hline \multirow{2}{*}{\multicolumn{2}{|c|}{ Total }} & Jumlah & 14 & 19 & 11 & 44 \\
\hline & & $\%$ total & $31.8 \%$ & $43.2 \%$ & $25.0 \%$ & $100 \%$ \\
\hline
\end{tabular}

Berdasarkan pada tabel diatas, variabel pola makan terdapat $45,5 \%$ anak berpola makan baik, $47,7 \%$ berpola makan cukup baik dan 6,8\% anak berpola makan buruk. Dari variabel aktivitas fisik terdapat 31,8\% anak beraktivitas fisik baik, $43,2 \%$ anak berpola makan cukup baik dan 25\% anak beraktivitas fisik kurang baik.

Dari tabel silang diatas juga didapatkan gambaran pola makan dan aktivitas fisik anak penderita obesitas di SDN Kauman 1 Malang bahwa terdapat 20,5\% berpola makan dan aktivitas fisik baik, $18,2 \%$ berpola makan baik dan beraktivitas fisik cukup baik, 6,8\% berpola makan baik dan beraktivitas fisik kurang baik. 11,4\% berpola makan cukup baik dan beraktivitas fisik baik, 25\% berpola makan dan beraktivitas fisik cukup baik, $11,4 \%$ berpola makan cukup baik dan beraktivitas fisik kurang baik, 6\% berpola makan kurang baik dan beraktivitas fisik kurang baik. Sementara itu untuk pola makan kurang baik dan aktivitas fisik baik serta pola makan kurang baik dan aktivitas fisik cukup baik tidak ada responden yang memiliki gambaran tersebut. 


\section{PEMBAHASAN}

Deskripsi Karakteristik Responden

Berdasar usia

Dari hasil kuesioner diperoleh data penderita obesitas pada anak usia sekolah dasar (6-12 tahun) di SDN Kauman 1 Malang berada pada level diatas $12 \%$ kecuali usia 6 tahun yang hanya $2 \%$. Hasil ini sejalan dengan penelitian Dr. Damayanti yang tergabung dalam Masyarakat Pediatrik Indonesia pada periode 2002 - 2005 bahwa rata-rata prevalensi obesitas anak di Indonesia adalah $12.2 \%$.

Jenis Kelamin

Berdasar jenis kelamin ada 23.52\% untuk perempuan dan $21.48 \%$ untuk laki-laki dimana data ini menjelaskan bahwa perempuan lebih besar dalam terjadinya obesitas. Hal ini sejalan dengan pernyataan Dietary Energy Consultative Group (1989), bahwa perempuan sedikit lebih gemuk dari pada laki-laki pada saat kelahiran sampai bayi dan anakanak. Hal ini dikarenakan komposisi tubuh antara jenis kelamin berbeda yang mungkin disebabkan faktor endokrin dan hormonal. Hasil ini juga mendukung asumsi bahwa laki-laki lebih aktif dan lebih banyak melakukan aktivitas yang mengeluarkan energi dibandingkan dengan perempuan yang kurang mengeluarkan energi dalam aktivitasnya.

\section{Pengaruh Pola Makan}

Variabel pola makan dalam penelitian ini digambarkan dengan jumlah susu yang diminum, frekuensi makan sehari, frekuensi makan makanan kudapan dan frekuensi makan makanan cepat saji. Keempat determinan ini akan diubah terhadap suatu penilaian pola makan yaitu baik, cukup baik dan kurang baik.

Pada determinan jumlah susu yang diminum pilihan terbanyak ada opsi c yaitu jumlah minum susu perhari adalah 1 gelas (baik) sejumlah $55 \%$ responden diikuti oleh opsi b yaitu minum susu 2-3 gelas perhari dengan jumlah responden $30 \%$ dan terdapat $16 \%$ responen minum susu lebih dari 3 kali dalam sehari. Hal ini memberi gambaran bahwa sebanyak $16 \%$ dari penderita obesitas di SDN Kauman 1 Malang mengkonsumsi lemak susu dalam sehari lebih dari 330 kalori (1 gelas susu ukuran rumah tangga sama dengan 110 kalori).
Sejalan dengan determinan jumlah minum susu perhari, determinan frekuensi makan tiap hari juga dalam posisi baik yaitu terdapat $89 \%$ responden mempunyai frekuensi makan yang baik. Sedangkan 57\% responden menyatakan tidak pernah nambah nasi tiap makan. Hasil ini tidak sesuai dengan pernyataan Hidayat (2009) bahwa anak dengan obesitas biasanya memiliki asupan tinggi lemak dan tinggi karbohidrat. Namun yang perlu diwaspadai bahwa terdapat $2 \%$ dari responden yang mempunyai frekuensi makan sehari lebih dari 5 kali dan terdapat $7 \%$ responden nambah nasi tiap makan lebih dari 1 kali. Untuk ukuran rumah tangga satu porsi piring nasi menggandung 175 kalori.

Determinan makan makanan kudapan dengan pertanyaan "tiap nonton TV, belajar atau bermain apakah anda sering ngemil?" menghasilkan jawaban ya (kurang baik) 34\%, jarang (cukup baik) $39 \%$ dan tidak pernah (baik) 27\%. Hal ini sejalan dengan pernyataan wahyu (2009) bahwa selama menonton TV anak biasanya dibarengi dengan mengudap makanan ringan, keripik, gorengan serta minuman yang tinggi gula. Kebiasaan mengudap makanan dan minuman ringan inilah yang menyebabkan obesitas pada anak.

Hasil dari determinan makan makanan cepat saji memberikan gambaran terdapat 50\% responden 2-4 kali mengkonsumsi makanan cepat saji (cukup baik), $19 \%$ satu kali (baik) dan 7\% lebih dari empat kali setiap bulannya (kurang baik). Hal ini menggambarkan bahwa gaya hidup responden yang gemar mengkonsumsi makanan cepat saji cukup tinggi. Hal ini sesuai dengan pernyataan Subardja (2004) yang mengatakan bahwa masyarakat kota lebih gemar mengkonsumsi makanan cepat saji dan pada umumnya makanan cepat saji tersebut tinggi kalori dan minim gizi.

Pengaruh Aktivitas Fisik

Seperti halnya pola makan, aktivitas fisik juga dibagi beberapa determinan yaitu durasi bermain, jenis permainan, durasi menonton TV, cara pergi ke sekolah. Keempat determinan ini akan diubah terhadap suatu penilaian aktivitas fisik yaitu baik, cukup baik dan kurang baik.

Determinan durasi bermain memberi gambaran bahwa sebanyak $27 \%$ responden menggunakan waktu bermainnya 1 jam, 43\% menggunakan 2-3 jam untuk bermain dan 30\% menggunakan waktu bermain lebih dari 3 jam. 
Sementara itu dari determinan jenis permainan yang sering dilakukan menunjukkan sebanyak 55\% anak melakukan permainan dengan katagori kurang baik (permainan modern yang kurang mengeluarkan energi), 9\% cukup baik (permainan yang cukup mengeluarkan energi) dan 36\% baik yaitu permaian yang banyak mengeluarkan energi. Hal ini sejalan dengan pernyataan Wahyu (2009) bahwa permaian modern cenderung menghabiskan banyak waktu, membuat anak malas bergerak dan enggan bersosialisasi dengan teman sebayanya.

Determinan menonton TV menggambarkan 23\% anak menggunakan waktunya untuk menonton TV selama lebih dari 5 jam, 25\% menggunakan waktunya 3-4 jam dan $52 \%$ menggunakan 1-2 jam waktunya untuk menonton TV. Hal ini didukung dengan pernyataan hidayat bahwa setiap hari anak akan meluangkan waktunya sekitar 3-4 jam untuk menonton TV dan Menurut Meenu dan Madhu (2001), menyatakan bahwa kehilangan aktivitas fisik, akibat menonton televisi atau bermain video game lebih dari 1 (satu) jam setiap hari memiliki kontribusi yang signifikan terhadap obesitas pada anak. Hal ini juga dapat dikaitkan dengan determinan makan makanan kudapan karena selama menonton TV anak biasanya dibarengi dengan mengudap makanan ringan seperti keripik, gorengan serta minuman yang tinggi gula.

Sementara itu, dari determinan cara pergi ke sekolah yang juga menggambarkan jumlah energi yang digunakan, terdapat 95\% anak pergi ke sekolah dengan menggunakan fasilitas antar jemput, hanya $3 \%$ yang bersepeda dan $0 \%$ jalan kaki. Hal ini dapat diasumsikan bahwa anak penderita obesitas di SDN Kauman 1 Malang berada pada tingkat sosial ekonomi yang tinggi atau bias diasumsikan oleh faktor lain seperti lokasi sekolah jauh dari lokasi tempat tinggal penderita. Namun data penelitian tersebut mempertegas pernyataan Musaiger (2004) bahwa perubahan gaya hidup dan status sosial ekonomi di negara-negara Mediternia Timur, berdampak pada aktivitas fisik. Ketersediaan kenderaan, peningkatan peralatan elektrikal rumah tangga menyebabkan hidup lebih santai.

Dari berbagai faktor risiko yang dibahas diatas, masih terdapat faktor risiko yang berperan yaitu faktor genetik dimana pada penelitian ini tidak diteliti. Hasil yang didapat pada penelitian ini tentunya faktor genetik juga member peran. Hal ini dapat di buktikan dengan terdapatnya nilai z-skor
BB/TB sangat tinggi yaitu 10,05 (data terlampir). Maka dari itu perlu penelitian lebih lanjut untuk membahas faktor genetik dalam terjadinya obesitas pada usia anak sekolah dasar.

Analisis Data

Dari uji korelasi yang dilakukan bahwasannya terdapat korelasi yang bermakna antara pola makan dan aktivitas fisik dengan terjadinya obesitas dimana telah didapat nilai signifikan korelasi (r) pola makan sebesar 0.018 dan nilai signifikan korelasi (r) aktivitas fisik sebesar 0.024 terhadap obesitas lebih kecil dari signifikan korelasi yaitu 0.05 .

Kemudian untuk menjawab hipotesis penelitian maka dilakukan uji regresi linier dan melalui tabel anova akhirnya didapatkan nilai regresi (F) 3.910 dan nilai sig. $0.028<0.05$. Nilai ini dapat diartikan bahwa terdapat pengaruh yang signifikan antar pola makan dan aktivitas fisik anak terhadap terjadinya obesitas pada anak usia sekolah dasar di SDN Kauman 1 Malang.

Hasil uji diatas sepaham dengan pernyataan Subardja (2004) bahwa perubahan pola makan (pola konsumsi pangan) anak pada zaman sekarang baik di negara maju maupun negara berkembang termasuk Indonesia, khususnya di kota besar dan pada golongan sosial ekonomi tertentu, yaitu adanya kecenderungan untuk mengkonsumsi makanan dengan kalori berlebihan disertai dengan kurangnya aktivitas fisik menyebabkan insiden berat badan lebih dan obesitas pada anak juga cenderung makin meningkat.

Untuk mengetahui faktor mana yang lebih dominan mempengaruhi terjadinya obesitas pada anak di SDN Kauman 1 Malang, maka dilakukan uji signifikansi t dengan perhitungan perkalian nilai korelasi (r) tiap faktor risiko dengan nilai $B$ dari tabel koefisien (terlampir) dikali dengan 100. Dan didapat hasil pola makan $8.7576 \%$ dan aktivitas fisik $7.2760 \%$. Dari hasil perhitungan tersebut didapatkan bahwa faktor pola makan lebih berperan dalam terjadinya obesitas pada anak usia sekolah dasar di SDN Kauman 1 Malang. Hasil ini berbeda dengan pernyataan Subardja dkk (2000) menyatakan bahwa bila dibandingkan besarnya hubungan antara pola makan dan aktivitas fisik, ternyata pola aktivitas fisik lebih berhubungan dengan terjadinya obesitas pada anak. Hal ini mencerminkan pola hidup sedentary berkontribusi dalam terjadinya obesitas pada anak. Menurut asumsi dari penelitian yang 
sudah dilakukan hal ini diduga karena siswasiswi di SDN Kauman 1 Malang telah mendapatkan mata pelajaran olah raga sebagai bentuk aktivitas fisik yang dilakukan seorang anak penderita obesitas.

Perlu diingat, faktor risiko terjadinya obesitas bukan hanya pola makan dan aktivitas fisik, namun genetik juga berpengaruh. Hasil dari nilai z-skor yang dimiliki penderita obesitas di SDN Kauman 1 Malang, terdapat penderita yang mempunyai nilai z-skor 10,05. Meskipun tidak ada landasan teori yang pasti, dengan tingginya nilai zskor seorang anak penderita obesitas dimungkinkan karena faktor genetik yang mempengaruhinya.Maka dari itu perlu dilakukan penelitian lebih lanjut guna mengetahui faktor risiko genetik terhadap kejadian obesitas pada anak.

Hasil tabel silang pola makan dan aktivitas fisik telah menggambarkan terdapat $25 \%$ penderita obesitas di SDN Kauman 1 Malang berpola makan dan beraktivitas fisik cukup baik, namun terdapat 6,8\% penderita yang mempunyai pola makan dan aktivitas fisik yang kurang baik. Hasil ini perlu mendapat perhatian dari pihak sekolah dan orang tua demi masa depan kehidupan mereka selanjutnya karena obesitas pada anak mempunyai konsekuensi medis yang serius untuk masa depan yang bersangkutan maupun terhadap ketersediaan kualitas manusia Indonesia selanjutnya (Subarja, 2004)

\section{KESIMPULAN DAN SARAN}

Kesimpulan

Berdasarkan dari hasil penelitian ini dapat ditarik kesimpulan:

1. Terdapat hubungan yang bermakna antara pola makan dan aktivitas fisik anak dengan obesitas di SDN Kauman 1 Malang

2. Pola makan pada anak penderita obesitas di SDN Kauman 1 Malang 45.5\% dalam katagori baik, 47.7\% dalam katagori cukup baik dan 6.8\% dalam katagori kurang baik.

3. Aktivitas fisik pada anak penderita obesitas di SDN Kauman 1 Malang 31.8\% dalam katagori baik, 43.2\% dalam katagori cukup baik dan 25\% dalam katagori kurang baik.
4. Prevalensi obesitas di SDN Kauman 1 Malang mencapai 20,2\% dengan jenis kelamin penderita obesitas banyak pada anak perempuan

Saran

Berdasarkan kesimpulan dan pembahasan hasil penelitian, dikemukakan saran-saran sebagai berikut:

1. Bagi SDN Kauman 1 Malang

Hasil enelitian ini dapat dijadikan sebagai pedoman bagi SDN Kauman 1 Malang untuk memperhatikan siswa penderita obesitas, khususnya siswa obesitas yang mempunyai pola makan dan aktivitas fisik kurang baik demi masa depan mereka kedepannya.

2. Bagi orang tua

Hasil penelitin ini dapat digunakan sebagai dasar untuk memberikan pola makan dan aktivitas fisik yang baik kepada anaknya yang menderita obesitas dan juga sebagai pencegahan terjadinya obesitas pada anak yang berpotensi akan terjadinya obesitas pada masa yang akan datang.

3. Bagi penelitian berikutnya

Hasil penelitian ini dapat dijadikan sebagai studi pendahuluan untuk mengembangkan penelitian selanjutnya. Selain itu, perlu dilakukan penelitian lanjutan dengan memperluas variabel lain yang diduga juga dapat mempengaruhi terjadinya obesitas khususnya pada anak. 


\section{DAFTAR PUSTAKA}

Abunaim, Jumadias, 1990. Aplikasi Antropometri sebagai Alat Ukur Status Gizi, Puslitbang Gizi Bogor.

CDC-NCHS, Chilhood Overweight and Obesity, 2009 Viewed 26 Februari 2013 http:/ www.cdc.gov/obesity/childhood/index.html

Depkes, RI, 2004, Analisis Situasi Gizi dan Kesehatan Masyarakat, Jakarta.

I Dewa Nyoman Supriasa, Bachyar Bakrri, Ibnu Fajar, 2002. Penilaian Status Gizi, EGC, Jakarta.

Hidayat, Burhan Rudi Irawan, Siti Nurul Hidayati, Obesitas Pada Anak. Divisi Nutrisi dan Penyakit Metabolik Bagian/SMF Ilmu Kesehatan Anak.FK Unair, Surabaya.2009.

Krisno, Moch, 2002, Gizi dan Kesehatan, Edisi Pertama, Desember 2002, Jakarta.

Meenu Singh, Madhu Sharma, 2005, Risk Factors for Obesity in Childreen, Departemen of Pediatric, Advanced Pediatric Centre, Postgraduate Institute of Medical Education and Research, Chandigard, India.

Musaiger,A.O., 2004. Overweight and Obesity in the Eastern Mediterranian Region : Can We Control It?., Eastern Mediterranian Health Journal.

Notoatmodjo, Soekidjo.2005., Metodologi Penelitian Kesehatan, Rineka Cipta, Jakarta.

Ranuh, I.G.N Gde, 1995, Tumbuh Kembang Anak, EGC : Jakarta

Sastro, Asmoro - Sofyan Ismael. 1995, DasarDasar Metodologi Penelitian Klinis. Binarupa Aksara: Jakarta,

Sediaoetama, Achmad Djaeni, 2006. Ilmu Gizi Untuk Mahasiswa dan Profesi Jilid 1. Dian Rakyat:: Jakarta

Simatupang, Romauli. 2008, Pengaruh Pola Konsumsi, Aktivitas Fisik dan Keturunan Terhadap Kejadian Obesiatas Pada Siswa Sekolah Dasar Swasta DI Kecamatan Medan Baru Kota Medan. Sekolah Pasca Sarjana Universitas Sumatera Utara. Medan

Suarthana, Eva.dkk.Prevalensi Obesitas pada Anak Usia 4-6 Tahun dan Hubungannya dengan Asupan Serta Pola Makan. Majalah Kedokteran Indonesia, Volume 57, Nomor: 2,2007
Subardja, Dedi.2004.Obesitas Primer Pada Anak. Kiblat Buku Utama:Bandung

Staf Pengajar FKUI.1985.Ilmu Kesehatan Anak.Infomedika:Jakarta

UKS SDN Kauman 1 Malang, Buku Laporan Kesehatan Siswa SDN Kauman 1 Malang, 2011

Wahyu, Ginanjar Genis.2009.Obesitas Pada Anak. Bentang Pustaka: Yogyakarta

WHO. 1983. Measuring Change In Nutritional Status. Genewa

Yayah K. Husaini. Agustus 1997. Antopometri Sebagai Indikator Gizi dan Kesehatan Masyarakat. Medica, no 8 Tahun XXIII 